\title{
Using singing to nurture children's hearing? A pilot study
}

Graham F Welch ${ }^{1}$, Jo Saunders ${ }^{1}$, Sian Edwards ${ }^{2}$, Zoe Palmer ${ }^{4}$, Evangelos Himonides ${ }^{1}$, Julian Knight ${ }^{4}$, Merle Mahon ${ }^{3}$, Susanna Griffin ${ }^{2}$, and Deborah A Vickers ${ }^{2}$

\author{
${ }^{1}$ University College London, Institute of Education, London \\ ${ }^{2}$ University College London, Ear Institute, London \\ ${ }^{3}$ University College London, Developmental Science Department, London \\ ${ }^{4}$ Creative Futures (United Kingdom)
}

\section{Abstract}

This article reports a pilot study of the potential benefits of a sustained programme of singing activities on the musical behaviours and hearing acuity of young children with hearing impairment (HI). Twenty-nine children ( $n=12 \mathrm{HI}$ and $n=17 \mathrm{NH}$ ) aged between 5 and 7 years from an innercity primary school in London participated, following appropriate ethical approval. The predominantly classroom-based programme was designed by colleagues from the UCL Institute of Education and UCL Ear Institute in collaboration with a multi-arts charity Creative Futures and delivered by an experienced early years music specialist weekly across two school terms. There was a particular emphasis on building a repertoire of simple songs with actions and allied vocal exploration. Musical learning was also supported by activities that drew on visual imagery for sound and that included simple notation and physical gesture. An overall impact assessment of the pilot programme embraced pre- and post-intervention measures of pitch discrimination, speech perception in noise and singing competency. Subsequent statistical data analyses suggest that the programme had a positive impact on participant children's singing range, particularly (but not only) for $\mathrm{HI}$ children with hearing aids, and also in their singing skills. HI children's pitch perception also improved measurably over time. Findings imply that all children, including those with $\mathrm{HI}$, can benefit from regular and sustained access to age-appropriate musical activities.

\section{Key words}

children, hearing impairment, music, benefits

\section{Introduction}

This article reports a pilot study of the potential benefits of a sustained programme of singing activities on the musical behaviours and hearing acuity of young children with hearing impairment (HI). There is evidence that children with $\mathrm{HI}$ using hearing aids (HAs) or cochlear implants (Cls) have poorer pitch perception and use a narrower vocal pitch range than their normal hearing $(\mathrm{NH})$ counterparts (Edwards, 2013; Looi and Radford, 2011). Also, it would be expected that children with $\mathrm{Cls}$ would perform more poorly than children with $\mathrm{HAs}$ due to the fact that $\mathrm{Cl}$ processing removes temporal fine structure cues, but there is very little evidence to date to indicate poorer pitch perception in children with $\mathrm{Cls}$ than those with HAs. 
Poor pitch perception is related to poor phonological representation, which in turn could impact on reading ability (Anvari et al, 2002). However, there is evidence that learning music enhances both sound perception (Schlaug et al, 2005) and phonological processing (Verney, 2013), not least because 'the human brain recruits similar cortical mechanisms for processing sound in both domains' (Strait \& Kraus, 2011: 133), i.e., sound processing in both music and speech (cf Kraus \& Slater, 2015; Patel, 2010; Patel, 2011; Sammler et al, 2009). In an overview of the impact of musical training on the development of auditory skills, Kraus and Chandrasekaran (2010) examined a wide range of neuroscientific studies and concluded that 'music training induces an enhancement of the processing of auditory signals' (op.cit.:601). Moreover, particular biases in musical experiences that relate to the musicians' biographies are reflected in the selective enhancement of particular aspects of auditory processing, such as whether the musician is a primarily a pianist, violinist, conductor or jazz performer. 'The effect of music training on brain plasticity is not just a 'volume-knob effect' - not every feature of the auditory signal improves to the same extent - but leads to the fine-tuning of auditory signals that are salient (with 'sound to meaning' significance)' (ibid).

In addition to adults, neuroplasticity and the possibility of transfer effects (the impact of experience in one domain on aspects of behaviour in another domain) are also evidenced in studies with children and adolescents. A recent series of longitudinal projects at the University of Helsinki, Finland revealed that musically trained school-aged children and preschool-aged children attending a musical playschool showed a more rapid maturation of sound discrimination than their control peers who did not take part in musical activities. Importantly, they found no evidence for 'pretraining group differences', i.e., the two groups had similar sound discrimination abilities at the onset of the music intervention, but differed significantly at the end (Putkinen et al, 2015). In these Finnish studies, the older children had undertaken a formal music programme, whereas the pre-school children had experienced less formal group music making activities. In both sets of participants, hearing acuity improved in relation to sustained musical experience. Similarly, with regard to adolescents, a two-year study of group music classes in three high (secondary) schools in the USA revealed that participants had an enhanced neural encoding of speech (Tierney et al, 2013) compared to controls experiencing a non-music intervention. Overall, there is a wealth of research evidence emerging that school-based and community-based music instruction can promote auditory processing, supporting speech and language acquisition skills (Anvari et al, 2002; Bidelman et al, 2013; Forgeard et al, 2008; Fujioka et al, 2006; Hille et al, 2011; Kraus et al, 2014; Kraus \& Strait, 2015; Schlaug 2015; Shahin, 2011; Slater et al, 2014; Tierney \& Kraus, 2013; Welch et al, 2012a; Wong et al, 2007; Zuk et al, 2013). In particular, early music-based intervention can impact positively on a wide range of developmental outcomes. This was illustrated in an Australian, large scale, longitudinal study involving 3,031 children. The study demonstrated that early shared music activities in the home from the age of 2-3 years had a demonstrable impact on the same children two years later at the ages of 4-5 years for vocabulary age, numeracy ability, attentional and emotional regulation, and prosocial skills (Williams et al, 2015). Similarly, Putkinen et al. (2013) reported that informal musical activities at home, including singing, can facilitate the sound discrimination and attention of 2-3 year old children.

Singing is a common cultural musical activity. Initially, young children's earliest vocal products relate to their affective state (such as discomfort or distress, or eustress-the latter characterised by euphonic cooing, e.g., Papousek [H], 1996). Subsequently, the interfacing of their neuropsychobiological design and sonic experiences within the maternal culture shapes the infant's 
pre-linguistic vocalisations to create a form of parent-child/self-other communication that draws on the prosodic features of the mother tongue (Papousek [M], 1996; Malloch, 1999 - see Welch, 2005 for an overview). The mother's infant-focused vocal communication (i.e., infant-directed speech and infant-directed singing-Trehub, 2001; Trehub and Gudmundsdottir, 2015) makes use of expressive prosodic contours, pitch glides and a prevalence of basic harmonic intervals ( $3 \mathrm{rds}$, 4ths, 5ths, octaves) in speech, as well as a repertoire of lullaby and play songs in singing.

In the case of $\mathrm{HI}$ children, pre-linguistic vocalisation tends to be somewhat delayed, and the onset of the use of canonical babbling, such as in consonant-vowel repetitive utterances (e.g. ba-ba) is later than seen for NH counterparts (Moeller et al, 2007a). By the age of 24 months HI children are reported by mothers as producing significantly fewer words than reported by the mothers of $\mathrm{NH}$ children (Moeller et al, 2007b). This same delay is also observed for children with Cls, resulting in under developed phonological abilities (Ertmer \& Goffman, 2011). One implication is that $\mathrm{HI}$ children have been unable to maximise the potential benefits from infant-focused vocal communication that accrues to their NH counterparts (cf. Fagan \& Pisoni, 2009).

Edwards (2013) explored the nature of musical development in $\mathrm{HI}$ children aged 4-9 years using either $\mathrm{HAs}$, $\mathrm{Cls}$ or both a $\mathrm{Cl}$ and a HA on different ears (bimodal; BM). Her findings indicated that there were no significant differences in the production of the habitual speech frequency (natural voice pitch) between $\mathrm{HI}$ participants and $\mathrm{NH}$ controls, but there were significant differences in the comfortable singing range (measured in semitones), pitch perception and also in their assessed singing competency of two well-known songs. HI children had a significantly reduced comfortable singing range and were likely to be skilled at singing. Nevertheless, the participant $\mathrm{HI}$ children enjoyed being involved in musical activities. The only aspects in which there were differences between children with Cls and those with HAs or BM systems were that they demonstrated even poorer pitch perception, had an even narrower fundamental frequency range and their voice quality was more irregular.

Torppa et al. (2014) investigated whether singing could facilitate auditory perception and attention of a group of Finnish children with $\mathrm{Cls}$ aged 4-13 years compared to NH controls. Detailed examination of the home backgrounds of the $\mathrm{Cl}$ children enabled the researchers to divide the group into singers and non-singers. Singers in the $\mathrm{Cl}$ group were reported to sing regularly at home, i.e., several times each week and a formal assessment of singing competency supported the singer/nonsinger classification. Auditory acuity data from a subsequent set of auditory perception tasks at two time points (focused on pre-attentive discrimination and attention shift toward changes in timbre, pitch, duration, and presence of temporal gaps in musical piano tones) revealed, as expected, that participants with Cls had difficulties in discriminating timbre and piano tone pitch compared to the $\mathrm{NH}$ controls. However, singers with Cls performed better than their non-singer counterparts on both timbre and pitch measures, implying that regular singing enhances aspects of auditory attention and perception.

There is evidence for $\mathrm{NH}$ children that singing competency tends to improve with age and experience across childhood, with older children usually being measurably more competent than their younger peers (e.g., Davidson, 1994; Mang, 2006; Tafuri, 2008; Welch et al 1997; Welch, 2006; Welch, 2009). However, in cases where children experience specific singing-focused interventions, such as happened recently from 2007 onwards in England under the National Singing Programme "Sing Up" 
for Primary schools, it is possible for singing competency to be accelerated, such that young children can be up to three years in advance of comparable children who have not had such experience (Welch et al, 2010; Welch et al, 2012b).

If singing ability can be improved, it is suggested that there will be transferrable benefits to other cognitive domains, such as auditory perception (Kraus and Chandrasekaran, 2010). A recent evaluation of a twenty-week classroom-based singing programme in East London revealed a significant improvement in young children's singing development and also in their reading skills compared to controls of similar age and background (Welch et al., 2012a). Comparable findings had been reported by Gromko (2005) with respect to the impact of active music making on the phonemic awareness of early readers, and also subsequently by Biggs et al (2008) on the reading fluency benefits of a singing software programme for struggling readers in a middle school setting. Most recently, Verney (2013) reported that an intervention based on rhythmic structure in either rhythmic speech or singing can be successful in improving young children's phonological skills.

Given that (a) singing competence is subject to developmental processes and open to improvement through pedagogical intervention, (b) beneficial links are evidenced between vocalisation and auditory perception, and (c) that singing has been shown to positively influence aspects of speech and language development (such as speech fluency, phonological development, vocabulary age and reading accuracy), the authors, representing specialist research teams in music education and hearing, led by Welch and Vickers respectively, collaborated to investigate whether a sustained music programme for $\mathrm{HI}$ children that was specifically focused on singing activities could have a positive impact on musical development, whilst also improving the hearing acuity of $\mathrm{HI}$ young children.

\section{Methods}

Funding: for this exploratory pilot study reported here was provided in 2013-2014 through a joint award from the Institute of Education (IOE), London and University College London (UCL) under their Strategic Partnership Research Innovation Fund, prior to the subsequent merger of the two institutions. Ethical approval for the study was obtained from the University College London Ethics Board (1297/004).

Location: The research was conducted at a large Primary school in London, UK, that offers integrated educational services for both $\mathrm{NH}$ and $\mathrm{HI}$ children in a geographical area that is both ethnically and culturally diverse. The proportion of children receiving specialist education for specific needs is high, being approximately a fifth, due to the school having a large $\mathrm{HI}$ unit for up to 68 children. A recent Ofsted (Office for Standards in Education) official inspection report (2012: 4) stated that the 'provision for $\mathrm{HI}$ pupils is well organised and managed' and that these pupils 'are fully involved in the life of the school and make good progress.'

Participants: Twelve $\mathrm{HI}$ children and seventeen $\mathrm{NH}$ children participated in the singing intervention. All the children were from school Years 1 and 2 (aged between five and seven years old). Six children had $\mathrm{Cls}$, three had a unilateral $\mathrm{Cl}$ in one ear and a $\mathrm{HA}$ in the contralateral ear (bimodal; $\mathrm{BM}$ ) and three used bilateral HAs. Exactly two-thirds of the HI children had English as the family language and 
this ratio held true when broken down into device type. For the NH group, 10 of the 17 children had an English family language background (59\%).

Singing intervention: Children had singing and vocal exploration sessions every week across two school terms (Spring and Summer, 2014) in two, ten-week batches, led by an expert in young children's singing development from Creative Futures, a multi-arts charity which delivers specialist arts projects with children of all ages across London. The programme was primarily class-based in which the $\mathrm{NH}$ and $\mathrm{HI}$ children participated together, with occasional small-group interactions (when time permitted) for pairs of $\mathrm{HI}$ children. Musical content embraced the building of a repertoire of simple songs with actions (sometimes practising lyrics without pitch, sometimes musical elements alone), vocal explorations (such as sirening a train sound, vocal rhythms, descending pitch glides, contrasting vocal timbres); tongue twisters (e.g., 'Swedish wristwatch'; 'red lorry, yellow lorry'); explorations in visual imagery for sound, using made up notation as well as gesture, and with software-based visual feedback in small group settings; sound imagery and metaphor (e.g., a dog panting; trumpet sounds), such as to build awareness of the voice mechanism (e.g., diaphragm). Class teachers and teaching assistants also attended each session in order to experience the programme and to utilise elements in their own teaching subsequently if they wished. The singing content was in line with suggested practice elements in the National Singing Programme 'Sing Up' in England and also what is known about effective singing pedagogy with children (Saunders et al, 2011; Welch et al, 2012b). Linguistic competency was not a pre-requisite in the pedagogical design for the singing programme, but rather there was an emphasis on vocal exploration, imitation and creativity in a broad soundscape.

Assessment: There were three elements to the assessment: (i) a singing competency profile, based on that used in the evaluation of the National Singing Programme (NSP) Sing Up (Welch et al, 2014); (ii) a specially design chord pitch discrimination test; and (iii) speech perception in noise. The NSP singing competency profile had three elements: (a) comfortable singing range in semitones; (b) a rating of singing competency that combined ratings against two complimentary developmental profiles (Rutkowski, 1997 and Welch, 1998) to create a normalised singing score (NSS) (out of 100) ${ }^{1}$; and (c) natural speech frequency, based on the child counting backwards from ten or twenty.

The chord task was a three-interval, three-alternate forced choice task, where one stimulus out of three was different. A pass or fail score was calculated for each contrast based on the binomial significance score for the $5 \%$ significance level $(p<0.05)$. The stimuli were synthesised piano-tones comprised of three note chords and the target stimulus was different by one semitone. Six chord contrasts were assessed three for a base note of $\mathrm{C} 4$ and three for a base note of G4. Stimuli were delivered and responses recorded on a laptop and the sounds were presented over an active Behringer B205D loudspeaker.

\footnotetext{
${ }^{1}$ The researcher would listen to each child's singing of two target songs (Twinkle, Twinkle and Happy Birthday) and make a judgement as to the level of competency displayed against the developmental criteria contained in each of the two rating scales (Rutkowski, 1997; Welch, 1998 - after Mang, 2006 - see Welch et al., 2012b for more detail). The researcher's rating of each child's two songs against each of the two independent measures of singing behaviour and development resulted in four measures that were combined and converted into a 'normalised singing score' (NSS), being a conversion of the rated measures into a percentage of the maximum ratings across the combined rating scales.
} 
Speech perception in noise was assessed using the children's coordinate response measure (based on Brungart, 2000). Each stimulus sentence took the form:

'Show the dog where the (colour) (number) is?': e.g. 'show the dog where the green three is?'

There were 6 colour options (blue, black, green, pink, red and white) and 8 possible numbers (1-9, excluding 7). Stimuli were spoken by a British female speaker.

The sentences were presented at $65 \mathrm{dBA}$ in the presence of a speech-shaped noise which was adjusted adaptively (2-down/1-up) on the basis of whether or not both the colour and number were identified correctly. Initial step size was $9 \mathrm{~dB}$, and decreased after two reversals to $3 \mathrm{~dB}$. A further 4 reversals were run and averaged to obtain the speech reception threshold (SRT).

Singing assessments were undertaken at baseline prior to beginning of the programme and repeated at the conclusion of the twenty weeks. The two other assessments were similarly conducted as baseline and post-intervention measures, and also at the intermediate point between the two, tenweek blocks.

\section{Results}

Statistical comparisons were made between the $\mathrm{HI}$ and the $\mathrm{NH}$ group. A repeated measures ANOVA with a within-subject factor of timepoint ( 3 test sessions) and a between-subject factor of hearing group (NH \& HI) were conducted for speech in noise (speech reception threshold (SRT)) and pitch perception testing. For the normalised singing score (NSS), natural speech frequency and comfortable singing range, a repeated measures ANOVA with factors of timepoint ( 2 test sessions) and hearing group ( $\mathrm{NH} \& \mathrm{HI}$ ) were used. For pairwise comparisons when there were three levels to the factor, a least significance difference test was conducted. The numbers of participants were too small to be able to conduct the analysis according to device type, but the data for this has been plotted to highlight potential trends.

\section{FIGURE 1}

The comfortable singing range changed significantly across sessions, as shown by a significant effect of time point $\left(F^{(1,20)}=6.37, p=0.02\right.$; see Figure 1$)$. There was also a significant difference between hearing groups $\left(F^{(1,20)}=4.47, p=0.047\right)$, but there was no significant interaction between timepoint and hearing status, indicating that both groups demonstrated an improvement over time.

A singing range of twelve semitones equates to an octave, and twenty-four semitones to two octaves, the latter being more than sufficient for the typical song repertoire of childhood. Figure 2 shows the results for comfortable singing range broken down into hearing device type. Detailed data analyses indicate that the largest improvements were seen for the HA users, whose scores developed to be within the normal hearing comfortable singing range by the end of the singing programme. 
With regard to the other singing measure, the normalised singing score (NSS), a similar pattern was seen in the data. There was a significant effect of time point $\left(F^{(1,20)}=9.72, p=0.005\right)$ (Figure 3 ) and also for hearing group $\left(\mathrm{F}^{(1,20)}=95.34, \mathrm{p}<0.001\right.$ ) (Figure 4). Children with $\mathrm{NH}$ tended to develop their song singing skills (as assessed by the NSS) in line with the national dataset for this age group (5-7 years), based on comparative data from an ongoing study of singing competency related to children's instrumental learning in the North of England (Welch et al 2015). There were also overall improvements for children in each hearing device group (see Figure 4). The NSS outcome measure was not purely based on pitch skills, as rhythmical aspects are a part in the derived NSS. Although the scores for $\mathrm{HI}$ children with all devices were poorer than for the NH children, there were positive group changes evidenced across the period of the singing intervention.

FIG 3

FIG 4

The findings for the natural speech frequency did not show a significant change over time $\left(F^{(1,19)}=0.39, p=0.54\right)$, nor a significant difference between hearing groups $\left(F^{(1,19)}=0.01, p=0.97\right)$. This is perhaps not surprising, given that natural speech frequency is closely related to both the physical size of the vocal apparatus (primarily the length of the vibrating portion of the vocal folds), but also to the gendered voice of childhood which is predominantly feminine, i.e., girl-like, with young boys tending to have the same speaking F0 and Long-Term Average Spectra (LTAS) as girls (Sergeant et al, 2005; Sergeant \& Welch, 2007; Welch \& Howard, 2002).

The results showed that there was a significant effect of time point $\left(F^{(2,54)}=5.87, p=0.005\right)$ and hearing group $\left(F^{(1,27)}=13.45, p=0.001\right)$ for the pitch perception task, but there was no interaction between time point and hearing status. Each time point (baseline, mid-programme, post-intervention) was significantly different from one another, demonstrating a continuing improvement over time (see Figure 5 for the group results). HI children were very poor at the task in the first session (with only two children scoring above zero), but they improved over time and, by the third session, eight children scored above zero. In contrast, all of the NH children were able to do the task to some extent and improved over time. Figure 6 presents the breakdown of pitch perception task results by device type, with all groups showing some degree of improvement over time. 
For the speech in noise SRT there was no significant effect of time point $\left(F^{(2,54)}=1.278, p=0.287\right)$, but there was a significant effect by hearing group $\left(F^{(1,27)}=78.99, p<0.001\right)$, indicating that $(a)$ there was no improvement over time on this measure and (b) that the $\mathrm{HI}$ group were significantly poorer at hearing speech in noise that their NH counterparts.

\section{Discussion}

This was an exploratory, pilot study to investigate whether a specially designed, twenty-week schoolbased programme of singing and vocal activities could nurture the musical development and hearing acuity of children with HI. The resultant data, comparing baseline with post-intervention measures, are encouraging. There was evidence of improvements in measures of sung vocal range and singing competency for the $\mathrm{HI}$ children, including those with $\mathrm{Cls}$, and also a noticeable improvement in children's accuracy on the piano chord pitch perception task. The study builds on earlier research (e.g., Edwards, 2013; Rocca, 2012; Torppa et al, 2014) that has suggested that musical experience in general, and singing in particular, could support augmented auditory perception and attention in $\mathrm{HI}$ children, given that production is linked to perception, as implied in the current study's results of increased musical skills and vocal competency. Other data from studies with $\mathrm{NH}$ children indicate that musical experience can have wider benefits (Williams et al., 2015; Putkinen et al., 2015), including across a wider auditory field for HI children (Putkinen et al, 2013; Rochette et al, 2014). The results reported above occurred in the context of a series of regular, classroom-based singing sessions, i.e., with $\mathrm{NH}$ and $\mathrm{HI}$ children learning together. Resources were insufficient to allow targeted singing activities with individual $\mathrm{HI}$ children, although there were some occasional small group $\mathrm{HI}$ sessions that allowed a more specific focus. One implication is that more sustained singing experience would potentially bring about even greater changes, particularly if the intervention was sufficiently early in the child's life when the possibility of transfer effects due to the brain's underlying plasticity are likely to be more evidenced. We were also aware that, in the small scale study reported here, the participant group of $\mathrm{HI}$ children was extremely heterogeneous, with a mixture of $\mathrm{HA}$ and $\mathrm{Cl}$ users and many children with complex additional needs. With a larger group of participants and a more sustained programme we can explore the data for $\mathrm{Cl}$ and $\mathrm{HA}$ users separately and determine which particular features of the musical intervention are likely to be most beneficial. The participant school was very pleased with the outcomes of this pilot study and so we have continued to provide a music programme into the current 2014-2015 academic year. Measurable outcomes of this extension should be available for analyses later in the year and will build on the initial pilot study data. We are also extending the singing and HI study into a secondary school setting to see if the age of $\mathrm{HI}$ participants might impact on the auditory outcomes. Overall, we suggest that the findings of the exploratory pilot study, in the context of the recent interest and evidence concerning the wider benefits of music (e.g., Hallam, 2015; Henriksson-Macaulay \& Welch, 2015; Schlaug, 2015), provide additional evidence to suggest that all children, and particularly those 
with hearing impairment, should have extended and rich musical experiences, both formally in school settings as well as informally in the home, pre-school and subsequently.

\section{Acknowledgements}

Research funded by an Institute of Education and University College London Strategic Partnership Research Innovation Fund. The authors would like to thank the staff, children and families at Laycock Primary School London for their engagement and enthusiasm with the programme.

Conflicts of interest: None

Ethical approval provided by UCL

\section{References}

Anvari, S. H., Trainor, L. J., Woodside, J., and Levy, B. A. (2002). Relations among musical skills, phonological processing, and early reading ability in preschool children. Journal of Experimental Child Psychology, 83, 111-130.

Bidelman, G.M., Hutka, S., \& Moreno, S. (2013). Tone Language Speakers and Musicians Share Enhanced Perceptual and Cognitive Abilities for Musical Pitch: Evidence for Bidirectionality between the Domains of Language and Music. PLOS ONE, 8(4): e60676 doi:10.1371/journal.pone.0060676

Biggs, M.C., Homan, S.P., Dedrick, R., Minick, V., \& Rasinski, T. (2008). Using an interactive singing software program: A comparative study of struggling middle school readers, Reading Psychology, 29(3), 195-213. doi:10.1080/02702710802073438

Brungart, D. S. (2000). Informational and energetic masking effects in the perception of two simultaneous talkers. Journal of the Acoustical Society of America, 109(3), 1101 - 1109.

Davidson, L. (1994). Songsinging by young and old: a developmental approach to music. In R. Aiello with J. Sloboda (Eds.), Musical Perceptions (pp. 99-130). New York: Oxford University Press.

Edwards, S. (2013). Pitch Perception, Production and Musical Development of Hearing Impaired Children. Unpublished PhD Thesis, London; University College London, UCL Ear Institute.

Ertmer, D.J., \& Goffman, L.A. (2011). Speech Production Accuracy and Variability in Young Cochlear Implant Recipients: Comparisons with Typically Developing Age-peers. Journal of Speech, Hearing and Language Research, 54(1), 177-189. doi: 10.1044/1092-4388(2010/09-0165

Forgeard, M., Winner, E., Norton, A., Schlaug, G., 2008. Practicing a musical instrument in childhood is associated with enhanced verbal ability and nonverbal reasoning. PLoS One, 3(10): e3566. doi: 10.1371/journal.pone.0003566

Fagan, M. K., \& Pisoni, D. B. (2009). Perspectives on multisensory experience and cognitive development in infants with cochlear implants. Scandinavian Journal of Psychology. 50, 457462. doi: 10.1111/j.1467-9450.2009.00743.x 
Fujioka, T., Ross, B., Kakigi, R., Pantev, C., Trainor, L.J., (2006). One year of musical training affects development of auditory cortical-evoked fields in young children. Brain, 129 (10), 2593-2608. doi: $10.1093 /$ brain/awl247

Gromko, J.E. (2005). The effect of music instruction on phonemic awareness in beginning readers. Journal of Research in Music Education, 53(3), 199-209. doi: 10.1177/002242940505300302

Hallam, S. (2015). The Power of Music - a research synthesis of the impact of actively making music on the intellectual, social and personal development of children and young people. London: International Music Education Research Centre/Music Education Council.

Henriksson-Macaulay, L., \& Welch, G.F. (2015). The musical key to babies cognitive and social development. International Journal of Birth and Parent Education. 2(2), 21-25. http://www.ijbpe.co.uk/index.php/87-issue-6/165-the-musical-key-to-babies-cognitive-andsocial-development

Hille, K., Gust, K., Bitz, U., \& Kammer, T. (2011) Associations between music education, intelligence, and spelling ability in elementary school. Advances in Cognitive Psychology 7, 1-6. doi: 10.2478/v10053-008-0082-4

Kraus, N., \& Chandrasekaran, B. (2010). Music training for the development of auditory skills. Nature Reviews Neuroscience, 11, 599-605.

Kraus, N., \& Slater, J. (2015). Music and language: relations and disconnections. In: G.G. Celesia \& G. Hickok (Eds.), Handbook of Clinical Neurology, Vol. 129. Amsterdam: Elsevier.

Kraus, N., Slater, J., Thompson, E., Hornickel, J., Strait, D.L., Nicol, T., \& White-Schwoch, T. (2014). Music enrichment programs improve the neural encoding of speech in at-risk children. The Journal of Neuroscience, 34(36), 11913-11918. doi:10.1523/jneurosci.1881-14.2014

Kraus, N., \& Strait, D.L. (2015). Emergence of biological markers of musicianship with school-based music instruction. Annals of the New York Academy of Sciences, 1337, 163-169. doi: $10.1111 /$ nyas. 12631

Looi, V., \& Radford, C. (2011) A comparison of the speech recognition and pitch ranking abilities of children using unilateral cochlear implant, bimodal stimulaton or bilateral hearing aids. International Journal of Pediatric Otorhinolaryngology, 75(4), 472-482. doi: http://dx.doi.org/10.1016/j.ijporl.2010.12.023

Malloch, S.N. (1999). Mothers and infants and communicative musicality. Musicae Scientiae, Special Issue, pp29-57.

Mang, E. (2006). The effects of age, gender and language on children's singing competency. British Journal of Music Education, 23(2), 161-174. doi:10.1017/S0265051706006905.

Moeller, M.P., Hoover, B., Putman, C., Arbataitis, K., Bohnenkamp, G., Peterson, B., Wood, S., Lewis, D., Pittman, A., \& Stelmachowicz, P. (2007a). Vocalizations of infants with hearing loss compared with infants with normal hearing: Part I-phonetic development. Ear and Hearing, 28(5), 605-627. doi: 10.1097/AUD.0b013e31812564ab 
Moeller, M.P., Hoover, B., Putman, C., Arbataitis, K., Bohnenkamp, G., Peterson, B., Estee, S., Lewis, D.E., Pittman, A.L., \& Stelmachowicz, P.G. (2007b). Vocalizations of infants with and without hearing loss-Part II: Transition to words. Ear and Hearing. 28(5), 628-642. doi: 10.1097/AUD.0b013e31812564c9

Papousek, H. (1996). Musicality in infancy research: biological and cultural origins of early musicality. In I. Deliege and J. Sloboda (eds), Musical Beginnings. (pp. 37-55). Oxford: Oxford University Press.

Papousek, M. (1996). Intuitive parenting: a hidden source of musical stimulation in infancy. In I. Deliege \& J. Sloboda (Eds.), Musical Beginnings (pp. 88-112). Oxford: Oxford University Press.

Patel, A. (2010). Music, biological evolution, and the brain. In: M. Bailar (Ed.), Emerging Disciplines. (pp. 91-144). Houston, TX: Rice University Press.

Patel, A.D. (2011). Language, music, and the brain: A resource-sharing framework. In: P. Rebuschat, M. Rohrmeier, J. Hawkins, and I. Cross (Eds.), Language and Music as Cognitive Systems. (pp. 289-311). Oxford: Oxford University Press.

Ofsted. (2012). Laycock Primary School. [Inspection report 100411 May 2012]

Putkinen, V., Tervaniemi, M., \& Huotilainen, M. (2013). Informal musical activities are linked to auditory discrimination and attention in 2-3-year-old children: an event-related potential study. European Journal of Neuroscience, 37, 654-661. doi: 10.1111/ejn.12049

Putkinen, V., Tervaniemi, M., Saarikivi, K., \& Huotilainen, M. (2015). Promises of formal and informal musical activities in advancing neurocognitive development throughout childhood. Annals of the New York Academy of Sciences, 1337, 153-162. doi: 10.1111/nyas.12656

Rocca, C. (2012). A different musical perspective: improving outcomes in music through habilitation, education, and training for children with cochlear implants. Seminars in Hearing. 33, 425-433. doi: 10.1055/s-0032-1329229

Rochette, F., Moussard, A., \& Bigand, E. (2014). Music lessons improve auditory perceptual and cognitive performance in deaf children. Frontiers in Human Neuroscience. 8:488. doi: 10.3389/fnhum.2014.00488

Rutkowski, J. (1997). The nature of children's singing voices: Characteristics and assessment. In B.A. Roberts (Ed.), The Phenomenon of Singing (pp. 201-209). St. John's, NF: Memorial University Press.

Sammler, D., Koelsch, S., Ball, T., Brandt, A., Elger, C. E., Friederici, A. D., Grigutsch, M., Huppertz, H. J., Knosche, T. R., Wellmer, J., Widman, G., \& Schulze-Bonhage, A. (2009). Overlap of musical and linguistic syntax processing: intracranial ERP evidence. Annals of the New York Academy of Sciences. 1169, 494-498. doi: 10.1111/j.1749-6632.2009.04792.x.

Saunders, J., Papageorgi, I., Himonides, E., Rinta, T., \& Welch, G.F. (2011). Researching the Impact of the National Singing Programme 'Sing Up' in England: Diverse approaches to successful singing 
in Primary settings. London: International Music Education Research Centre, Institute of Education.

Schlaug, G., Norton, A., Overy, K., \& Winner, E. (2005). Effects of music training on the child's brain and cognitive development. Annals of the New York Academy of Sciences, 1060: 219- 230.

Schlaug, G. (2015). Musicians and music making as a model for the study of brain plasticity. Progress in Brain Research, 217, 37-55. http://dx.doi.org/10.1016/bs.pbr.2014.11.020

Sergeant, D. C., Sjölander, P., \& Welch, G. F. (2005). Listeners' identification of gender differences in children's singing. Research Studies in Music Education, 25, 28-39.

Sergeant, D.C., \& Welch, G.F. (2009). Gender differences in Long-Term-Average Spectra of children's singing voices. Journal of Voice, 23(3), 319-336. doi:10.1016/j.jvoice.2007.10.010

Shahin, A. (2011). Neurophysiological Influence of Musical Training on Speech Perception. Frontiers in Psychology, 2:126 doi: 10.3389/fpsyg.2011.00126

Slater, J., Strait, D.L., Skoe, E., O'Connell, S., \& Thompson, E. (2014). Longitudinal effects of group music instruction on literacy skills in low-income children. PLOS ONE 9(11): e113383. doi:10.1371/journal.pone.0113383

Strait, D. L., \& Kraus, N. (2011). Can you hear me now? Musical training shapes functional brain networks for selective auditory attention and hearing speech in noise. Frontiers in Psychology, 2(113) 1-10. http://dx.doi.org/10.3389/fpsyg.2011.00113

Tafuri, J. (2008). Infant Musicality. Farnham, UK: Ashgate.

Tierney, A., Krizman, J., Skoe, E., Johnston, K., \& Kraus, N. (2013). High school music classes enhance the neural processing of speech. Frontiers in Psychology, 6(4:855). doi: 10.3389/fpsyg.2013.00855

Tierney, A., \& Kraus, N. (2013). Music training for the development of reading skills. Progress in Brain Research, 207:209 -241. doi:10.1016/B978-0-444-63327-9.00008-4

Torppa, R., Huotilainen, M., Leminen, M., Lipsanen, J., \& Tervaniemi, M. (2014). Interplay between singing and cortical processing of music: a longitudinal study in children with cochlear implants. Frontiers in Psychology, 5:1389 doi: 10.3389/fpsyg.2014.01389

Trehub, S.E. (2001). Musical predispositions in infancy. In R. J. Zatorre \& I. Peretz (Eds.), The Biological Foundations of Music (Vol. 930, pp.1-16). New York: Annals of the New York Academy of Sciences.

Trehub, S.E., \& Gudmundsdottir, H.R. (2015). Mothers as singing mentors for infants. In G.F. Welch, D.M. Howard, \& J. Nix. (Eds.), Oxford Handbook of Singing. New York: Oxford University Press.

Verney, J.P. (2013). Rhythmic Perception and Entrainment in 5-Year-Old Children. An Exploration of the Relationship between Temporal Accuracy at Four Isochronous Rates and its Impact on Phonological Awareness and Reading Development. Unpublished PhD Thesis, University of Cambridge, Faculty of Education. 
Welch, G. F. (1998). Early childhood musical development. Research Studies in Music Education, 11, 27-41

Welch, G. F. (2005). Singing as communication. In D. Miell, R. MacDonald \& D. J. Hargreaves (Eds.), Musical Communication. (pp.239-259). New York: Oxford University Press.

Welch, G.F. (2006). Singing and Vocal Development. In G. McPherson (Ed.), The Child as Musician: a handbook of musical development. (pp. 311-329). New York: Oxford University Press

Welch, G.F. (2009). Evidence of the development of vocal pitch matching ability in children. Japanese Journal of Music Education Research, 39(1), 38-47.

Welch, G.F., Himonides, E., Saunders, J., Papageorgi, I., Preti, C., Rinta, T., Vraka, M., Stephens Himonides, C., Stewart, C., Lanipekun, J., \& Hill, J. (2010). Researching the impact of the National Singing Programme 'Sing Up' in England: Main findings from the first three years (2007-2010). Children's singing development, self-concept and sense of social inclusion. London: International Music Education Research Centre, Institute of Education.

Welch, G.F., Himonides, E., Saunders, J., Papageorgi, I., \& Sarazin, M. (2014). Singing and social inclusion. Frontiers in Psychology. 5:803. doi: 10.3389/fpsyg.2014.00803.

Welch, G. F., \& Howard, D. (2002). Gendered voice in the cathedral choir. Psychology of Music, 30(1), 102-120.

Welch, G.F., Saunders, J., Hobsbaum, A., \& Himonides, E. (2012a). Literacy through music: A research evaluation of the New London Orchestra's Literacy through Music programme. London: International Music Education Research Centre, Institute of Education, University of London.

Welch, G.F., Saunders, J., Papageorgi, I., \& Himonides, E. (2012b). Sex, gender and singing development: Making a positive difference to boys' singing through a national programme in England. In S. Harrison, G.F. Welch, \& A. Adler (Eds.), Perspectives on Males and Singing. (pp37-54). London: Springer.

Welch, G.F., Saunders, J., Le Messurier, S., Sarazin, M., \& Himonides, E. (2015). In Harmony Opera North Year 2 2013-2014. London: International Music Education Research Centre, UCL Institute of Education

Welch, G.F., Sergeant, D.C. and White, P. (1997). Age, sex and vocal task as factors in singing "intune" during the first years of schooling. Bulletin of the Council for Research in Music Education, 133, 153-160.

Williams, K.E., Barrett, M.S., Welch, G.F., Abad, V., \& Broughton, M. (2015). Associations between early shared music activities in the home and later child outcomes: Findings from the Longitudinal Study of Australian Children. Early Childhood Research Quarterly, 31, 113-124. http://dx.doi.org/10.1016/j.ecresq.2015.01.004

Wong, P.C.M., Skoe, E., Russo, N.M., Dees, T., \& Kraus, N. (2007). Musical experience shapes human brainstem encoding of linguistic pitch patterns. Nature Neuroscience, 10, 420-422. 
Zuk, J., Andrade, P.E., Andrade, V.C.A., Gardiner, M., \& Gaab, N. (2013). Music, language and reading abilities of early Portuguese readers. Frontiers in Psychology, 4: 288. doi:

10.3389/fpsyg.2013.00288 


\section{FIGURE LEGENDS}

Figure 1: Comfortable singing range in semitones by hearing status ( $\mathrm{NH}$ and $\mathrm{HI}$ ) at baseline and at the end of the twenty-week singing intervention. (Test session $1=$ baseline; Test session 3 = post-intervention after twenty weeks)

Figure 2: Comfortable singing range in semitones by hearing status ( $\mathrm{NH}$ and $\mathrm{HI}$ ) and hearing device at baseline and at the end of the twenty-week singing intervention

Figure 3: Normalised singing score (NSS) by hearing status (NH and $\mathrm{HI}$ ) at baseline and the end of the twenty-week singing intervention

Figure 4: Normalised singing score (NSS) by hearing status (NH and $\mathrm{HI}$ ) and hearing device at baseline and at the end of the twenty-week singing intervention

Figure 5: Pitch test pass \% data for each time point (baseline, mid-programme, postintervention) by hearing status

Figure 6: Pitch test pass \% data for each time point (baseline, mid-programme, postintervention) by hearing status and hearing device 
Figure 1

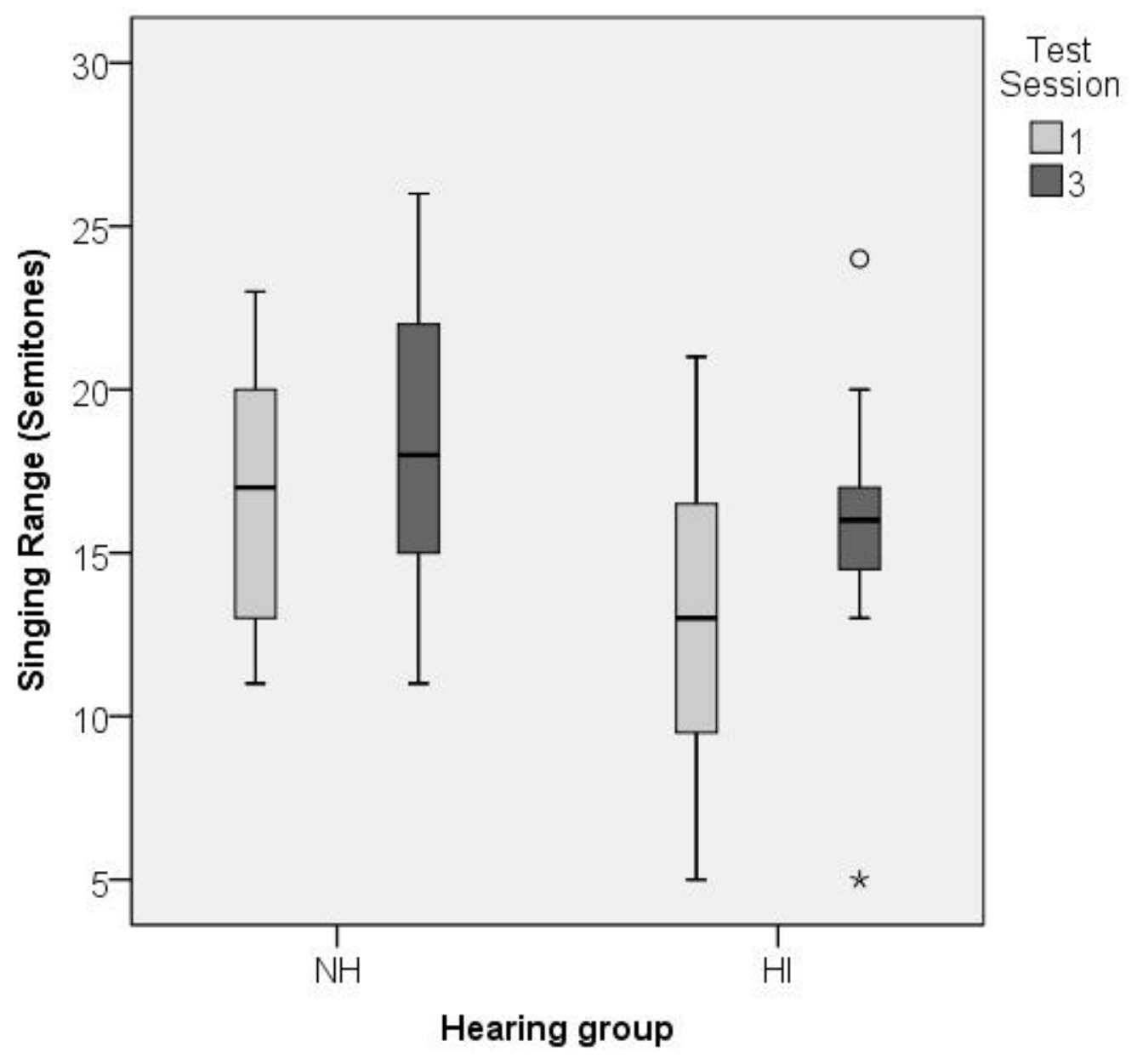


Figure 2

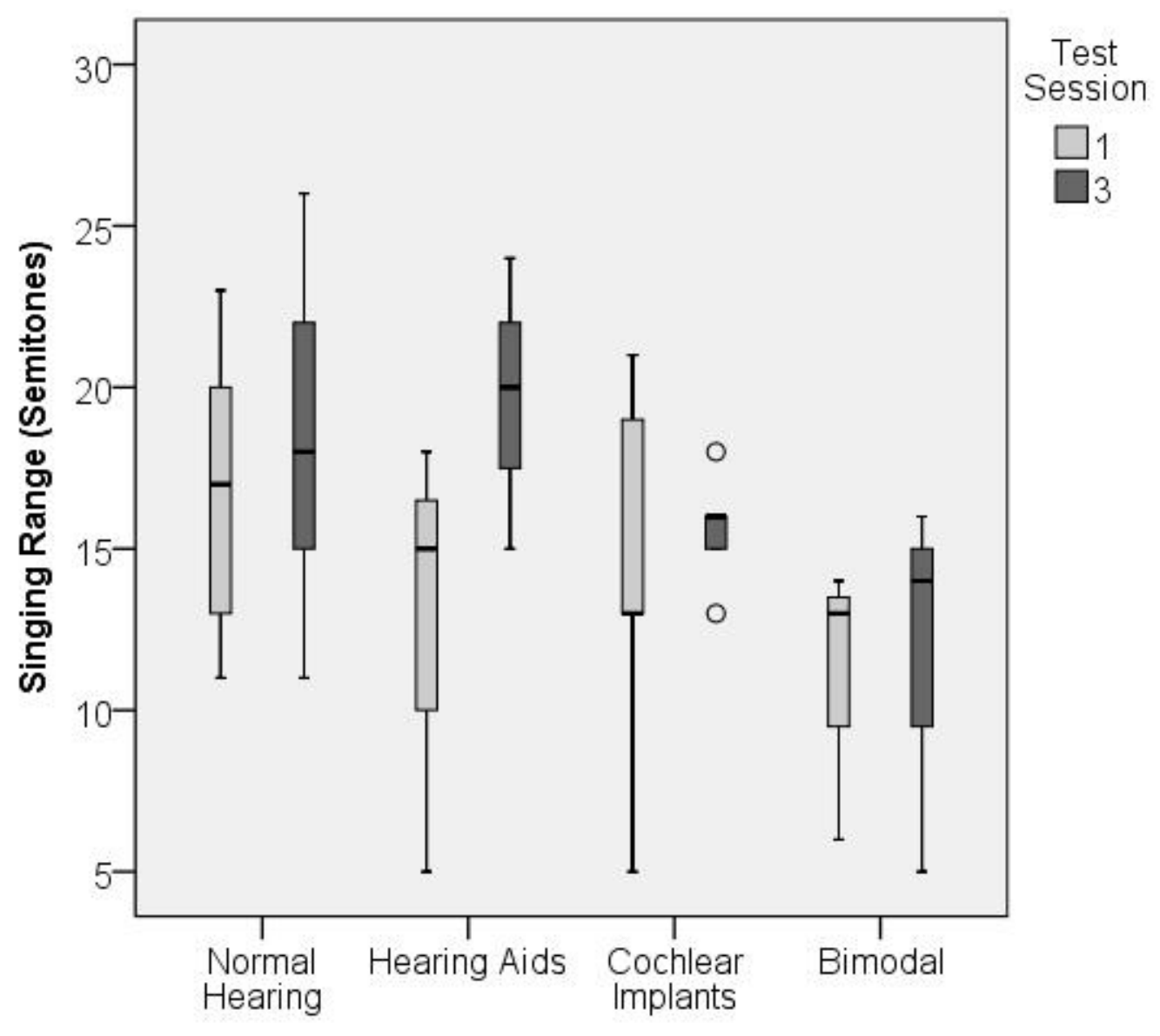


Figure 3

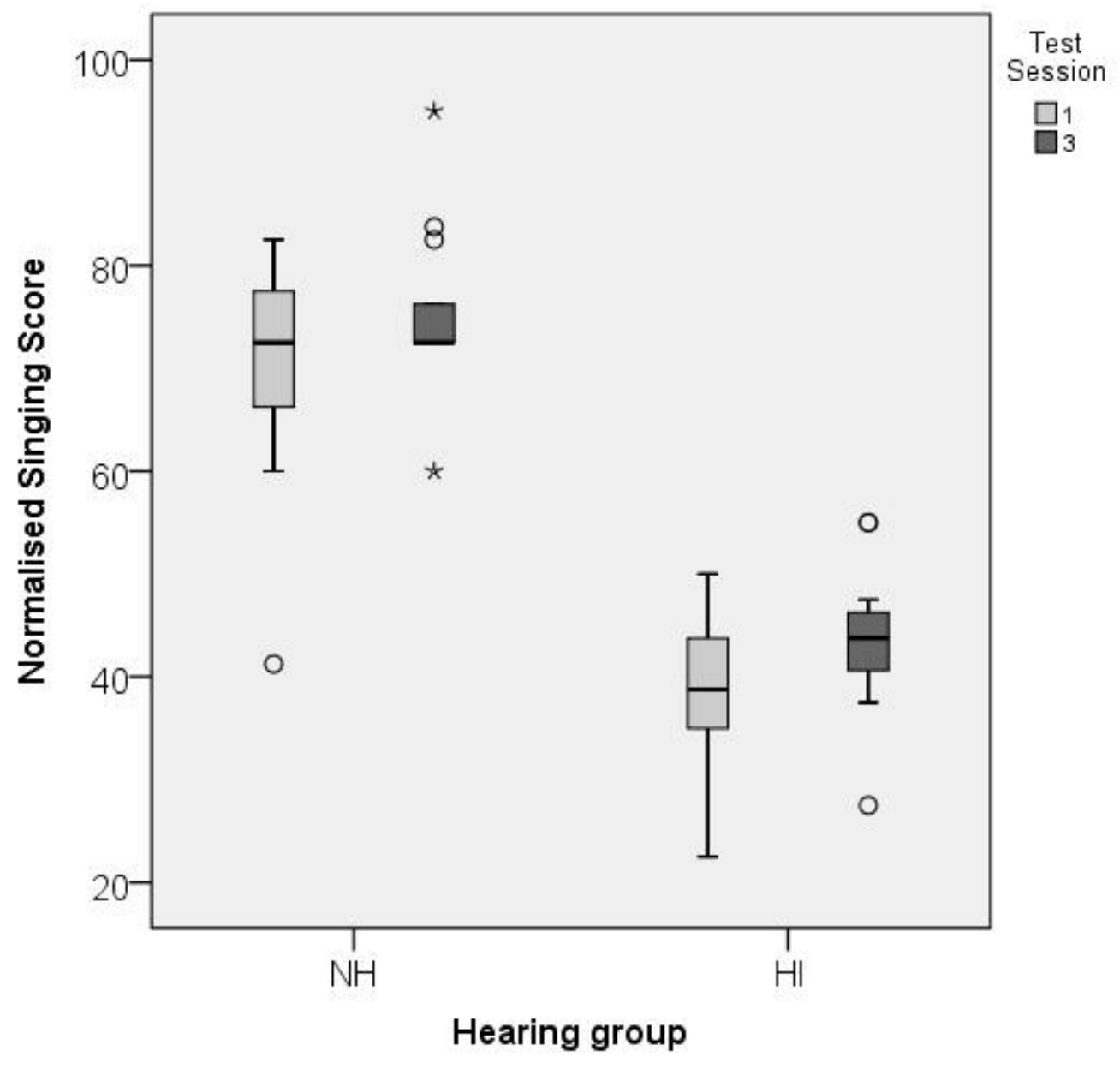


Figure 4

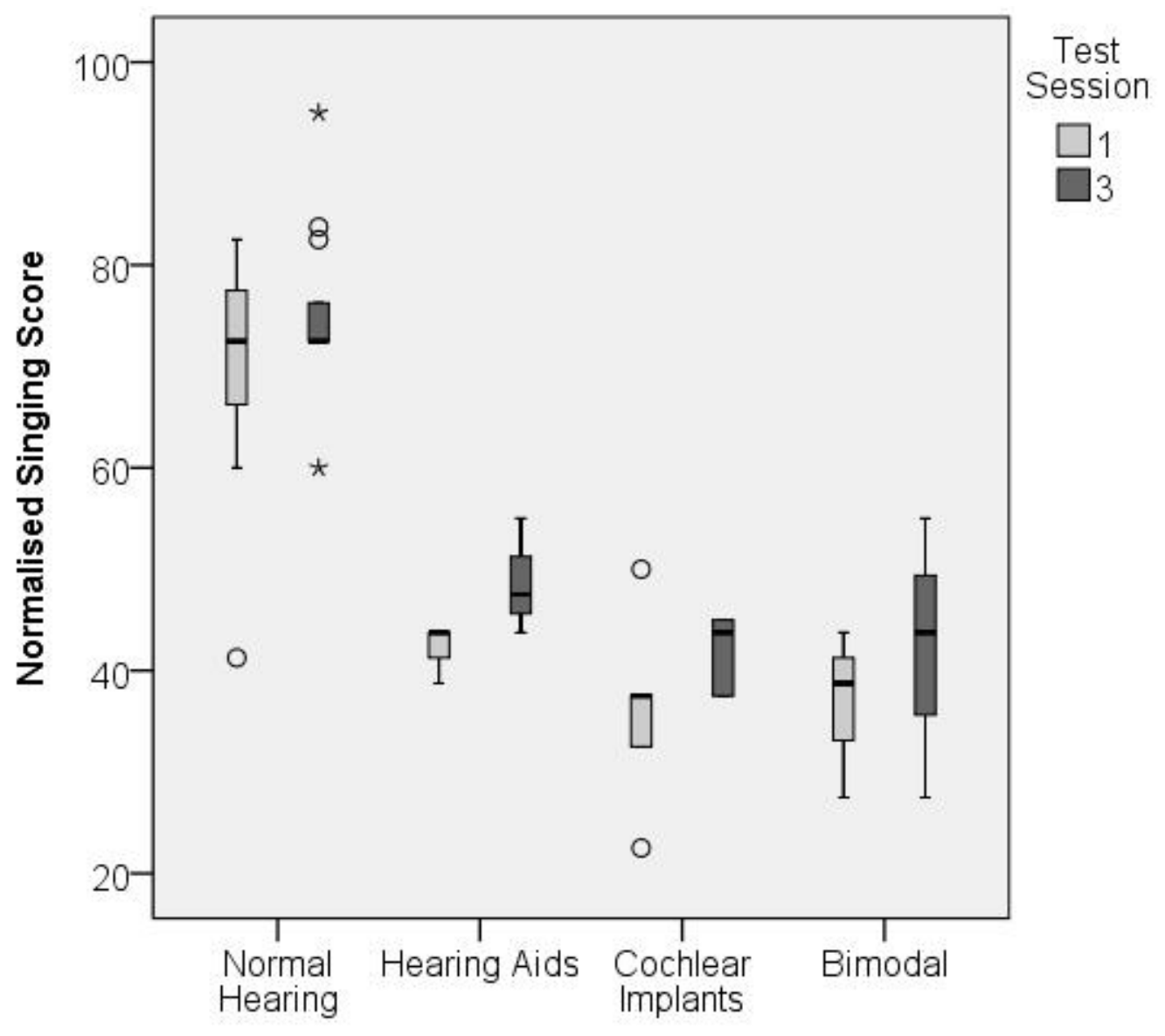


Figure 5

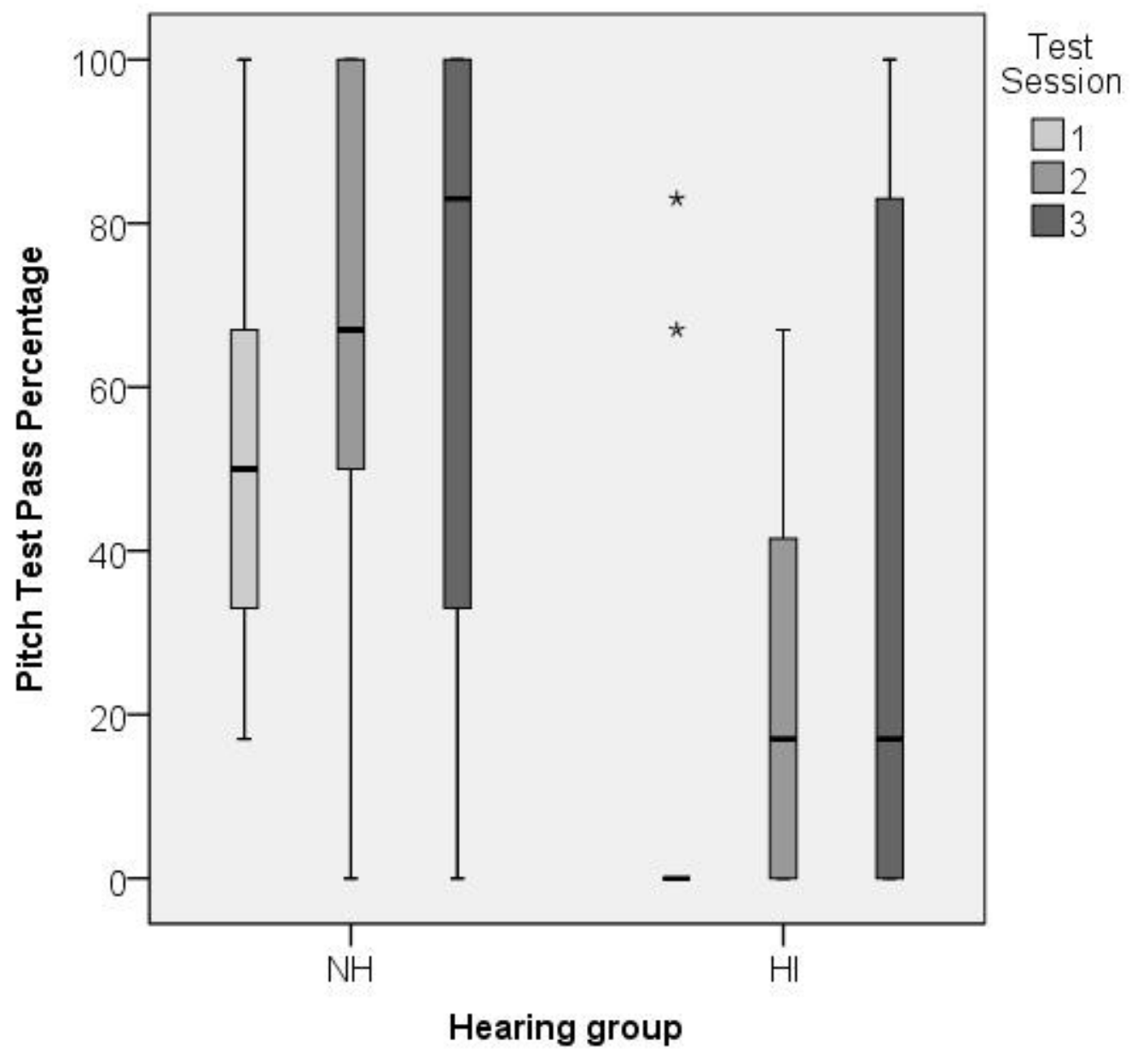


Figure 6

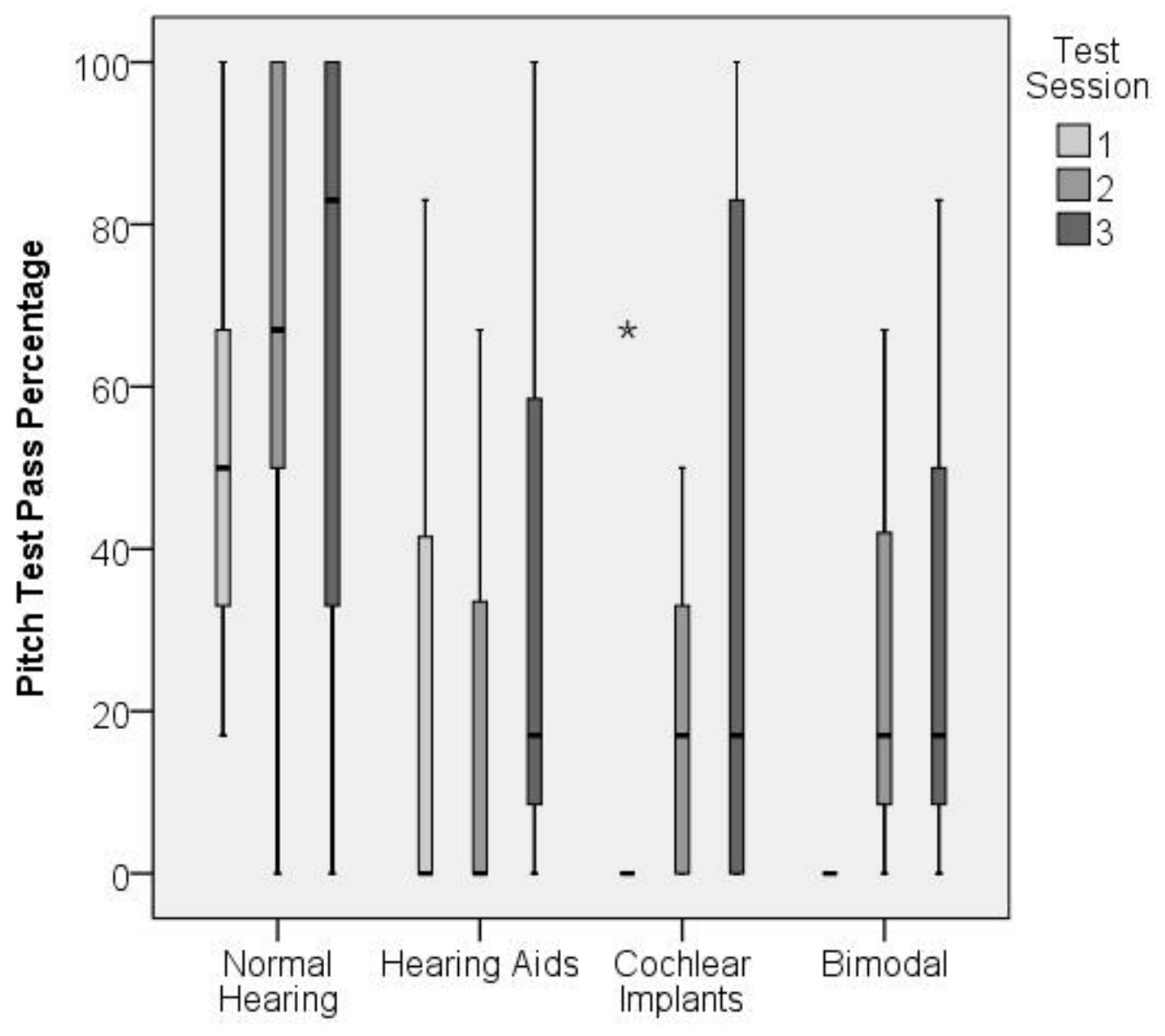

